\title{
SISTEM INFORMASI PEMESANAN PEMENTASAN SENI TARI BERBASIS WEBSITE STUDI KASUS SANGGAR CANGGET BUDAYA KOTABUMI LAMPUNG UTARA
}

\author{
Rima Mawarni ${ }^{1}$, Rianda Venia Audina ${ }^{2}$ \\ Program studi Sistem Informasi \\ STMIK Dian Cipta Cendikia Kotabumi \\ J1 Negara No.03 Candimas, Lampung Utara \\ rima@dcc.ac.id ${ }_{2}^{1}$ riandava027@gmail.com ${ }^{2}$
}

\begin{abstract}
ABSTRAK
Sanggar Cangget Budaya merupakan suatu organisasi yang bergerak dibidang seni tari. Untuk memberikan pelayanan yang lebih baik dan informasi terbaru kepada pelanggan, sanggar membutuhkan sebuah sistem yang dapat diakses oleh pelanggan dari manapun. Sistem ini nantinya akan mempermudah pelanggan untuk memperoleh informasi maupun mendapatkan pelayanan.

Adapun pengembangan yang digunakan dalam penelitian ini adalah dengan model Object Oriented yang menggunakan beberapa alat bantu seperti Use Case, Diagram Activity, Class Diagram dan Squence Diagram. Dan untuk metode pengembangan sistem yang digunakan adalah metode Prototype / Prototyping. Metode Prototype / Prototyping merupakan urutan aktivitas yang dimulai dari pengumpulan kebutuhan, membangun prototyping, evaluasi prototyping, mengkodekan sistem, menguji sistem, evaluasi sistem dan penggunaan sistem.
\end{abstract}

Diharapkan dengan adanya Sistem Informasi Pemesanan Pementasan Seni Tari Berbasis Website Study Kasus Sanggar Cangget Budaya Kotabumi Lampung Utara memudahkan para pengguna untuk memesan tarian dimanapun selama terhubung dengan internet dan dapat meningkatkan kinerja dan kualitas pelayanan.

Kata kunci : Sistem Informasi, Sanggar Cangget Budaya. 


\begin{abstract}
Sanggar Cangget Culture is an organization engaged in the art of dance.To provide a better service and the latest information to customers, its products are in need of a system that can be accessed by customers from anywhere.This system will make it easier for customers to obtain information or obtain a service.
\end{abstract}

As for development used in this research is the Object Oriented model using several tools such as Use Case, Activity Diagrams, Class diagrams and Squence Diagram.And for system development method that is used is the method Prototype/Prototyping.The method Prototype/Prototyping is the sequence of activities that started from the collection needs, build a prototyping, prototyping, evaluation, test systems encode system, evaluation system and the use of the system.

Expected by the existing Systems of information Ordering Performances Dance Studio Case Study-based websites Cangget Kotabumi North Lampung Culture makes it easy for users to order dance anywhere over the internet and can be connected to improve the performance and quality of service.

Keywords: information systems, Visit Cangget. 


\section{PENDAHULUAN}

Sanggar Cangget Budaya merupakan sanggar tari yang bergerak di bidang jasa yang dituntut untuk mengutamakan kualitas tarian yang ditampilkan kepada masyarakat terutama pemesan tarian. Saat ini Sanggar Cangget Budaya belum memiliki Sistem Informasi Berbasis Website untuk menyampaikan informasi sehingga masih ada keterbatasan dalam menyampaikan informasi, diantaranya informasi data tarian yang tersedia di Sanggar Cangget Budaya serta biaya untuk pemesanan pertariannya.

Oleh karena itu, diperlukan satu sistem informasi berbasis web yaitu Sistem Informasi Pemesanan Pementasan Seni Tari Pada Sanggar Cangget Budaya, supaya informasi mengenai tarian yang tersedia dan informasi biaya tarian dapat tersampaikan kepada masyarakat yang membutuhkan. Diperlukan metode yang praktis dalam meyediakan data dan informasi agar dapat dijadikan daya tarik pelanggan yang cepat salah satunya dengan sistem informasi pemesanan berbasis web[1]. Sehingga dipandang sangat diperlukan sebuah Website sehingga wilayah atau jangkauan penyebaran informasi dan pelayanan menjadi lebih luas, khususnya didalam Kabupaten Lampung Utara. Berdasarkan penjelasan diatas, peneliti bermaksud membahas penelitian dengan judul : "SISTEM INFORMASI PEMESANAN PEMENTASAN SENI TARI BERBASIS WEBSITE STUDI KASUS SANGGAR CANGGET BUDAYA KOTABUMI LAMPUNG UTARA".

\section{METODOLOGI PENELITIAN}

\subsection{Metode Pengembangan Sistem}

Adapun Tahapan-tahapan dalam pengembangan sistem menggunakan metode Prototyping adalah sebagai berikut :

1) Pengumpulan Kebutuhan

klien dan pengembang bersamasama mendefinisikan format software atau perangkat lunak, mengidentifikasikan kebutuhan dan sistem yang dibuat.

2) Membangun Prototype

Membangun prototype dengan membuat perancangan sementara yang berfokus penyajian kepada pelanggan (contoh membuat input dan format output).

3) Evaluasi Prototype

Tahap ini dilakukan oleh pelanggan atau klien, apakah prototyping yang dibuat atau dibangun, sudah sesuai dengan keinginan dan kebutuhan 
pelanggan atau belum. Jika tidak sesuai, prototyping akan direvisi dengan mengulangi langkahlangkah sebelumnya. Tapi jika sudah sesuai, maka langkah selanjutnya akan dilaksanakan.

4) Mengkodekan Sistem

Di tahap ini prototyping yang sudah disepakati diterjemahkan ke dalam bahasa pemrograman yang sesuai.

5) Menguji Sistem

Setelah sistem sudah menjadi suatu software yang siap pakai, maka software harus di tes dahulu sebelum digunakan. Hal ini bertujuan untuk meminimalisirkan kesalahan software tersebut. Pengujian dilakukan dengan Black Box, White box, Pengjian arsitektur, Basis path dan lain-lain.

6) Evaluasi Sistem

Di tahap ini pelanggan atau klien mengevaluasi sistem yang sudah dibuat sudah sesuai yang diinginkan. Jika tidak, maka pengembang akan mengulangi langkah ke 4 dan 5. Tapi jika iya, maka langkah ke 7 akan dilakukan.

7) Menggunakan Sistem
Prangkat Lunak atau Software yang telah diuji dan diterima klien atau pelanggan siap digunakan.

\section{A. Diagram Use case}

Peneliti menggunakan diagram Use case untuk menggambarkan bagaimana interaksi antara konsumen dengan sistem yang akan dibuat nanti, Berikut gambar diagram use case pemesanan pentas seni tari :

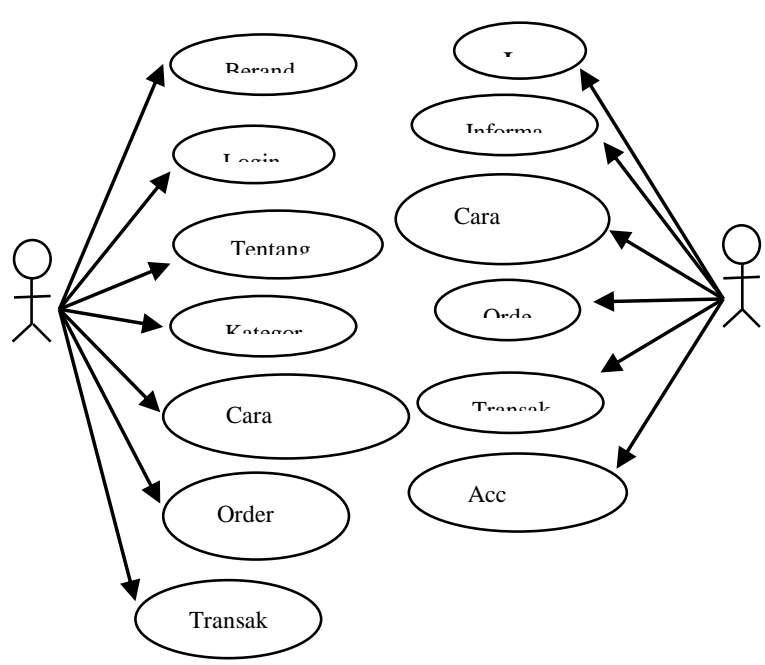

Gambar 1. Diagram Use Case Pemesanan Tiket

\section{B. Activity Diagram}

\section{Diagram Aktifitas (Activity) Admin}

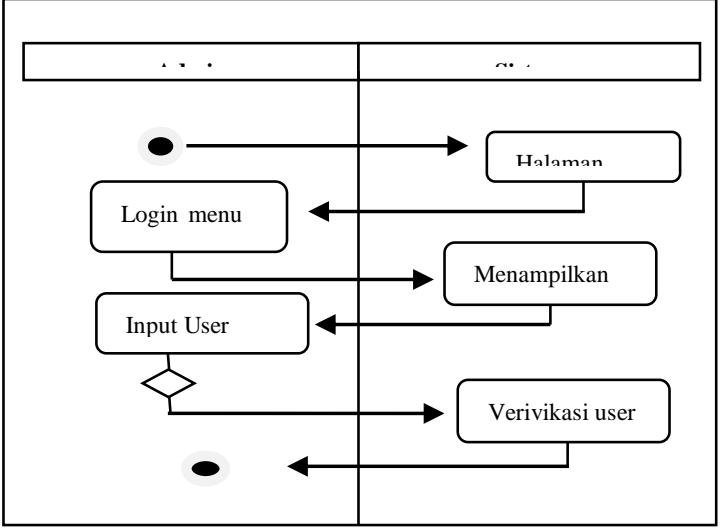


Gambar 2. Activity Diagram Login

\section{Admin}

2. Diagram Pelanggan

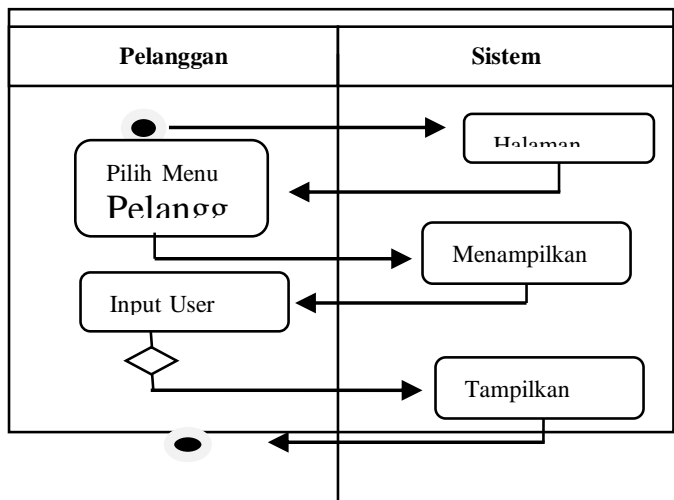

Gambar 3. Activity Diagram Login Pelanggan

\section{Diagram Sequence}

\section{Diagram Sequence Login Pelanggan}

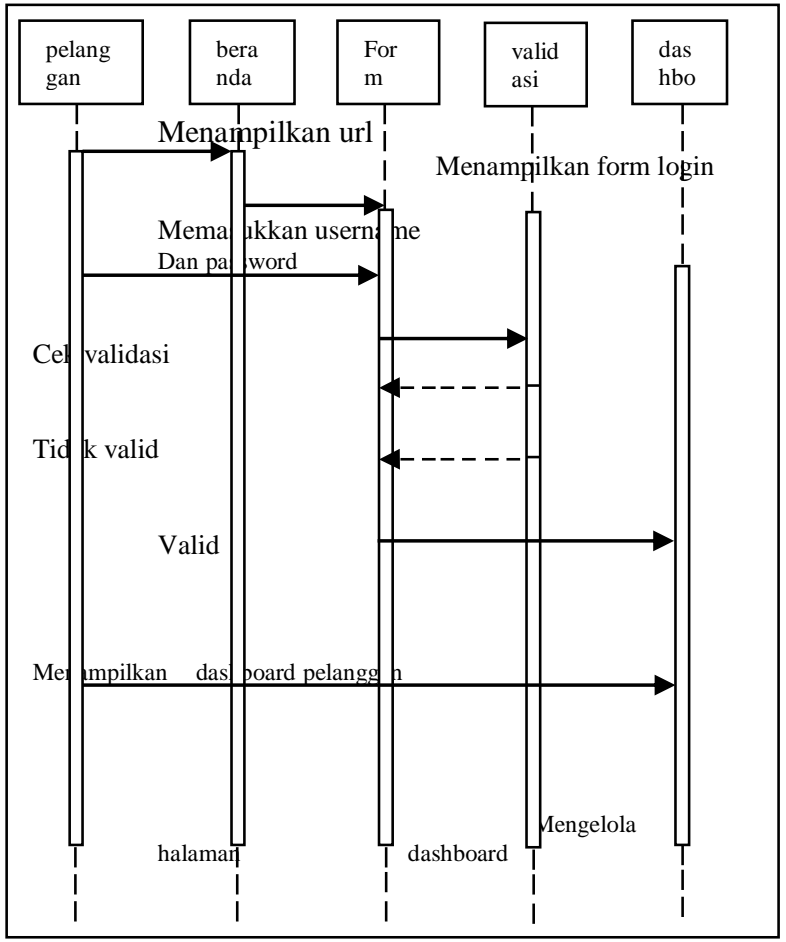

Gambar 4. Sequence Diagram Login Pelanggan
2. Diagram Sequence Konfirmasi Pembayaran

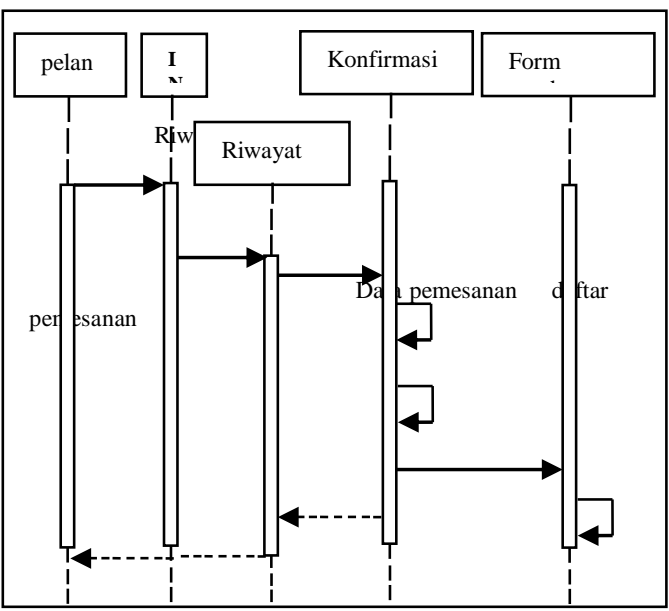

Gambar 5. Sequence

DiagramKonfirmasi Pembayaran

\section{Diagram Class}

Class diagram menggambarkan struktur sistem dari segi pendefinisian kelas-kelas yang akan dibuat untuk membangun sistem, Berikut diagram class pada sistem informasi pemesanan pementasan seni tari pada sanggar cangget budaya :

\begin{tabular}{|c|c|}
\hline Pelanggan SCB & Jenis Tarian \\
\hline \multirow{3}{*}{$\begin{array}{l}\text {-User_name } \\
\text { Nama_Pelanggan } \\
\text { Aalamat }\end{array}$} & \multirow{3}{*}{$\begin{array}{l}\text {-Nama_Tarian } \\
\text { Keterangan } \\
\text { Vntamni Trininn }\end{array}$} \\
\hline & \\
\hline & \\
\hline 33345345 & $\begin{array}{l}+ \text { Insert }() \\
+ \text { Edit }() \\
+ \text { Delete }()\end{array}$ \\
\hline Transaksi Pembayaran & Pemesanan \\
\hline \multirow{3}{*}{$\begin{array}{l}\text {-Id_Order } \\
\text { Id_Pembayaran } \\
\text { Jumlah Pemhavar }\end{array}$} & \multirow{3}{*}{$\begin{array}{l}\text {-User_name } \\
\text { Id_Kategori } \\
\text { Keterangan }\end{array}$} \\
\hline & \\
\hline & \\
\hline $\begin{array}{l}+ \text { Update () } \\
+ \text { Insert }()\end{array}$ & $\begin{array}{l}\text { + Insert () } \\
+ \text { +Edit } \\
+ \text { Delete }\end{array}$ \\
\hline & Laporan \\
\hline Admin SCB & \multirow{2}{*}{ Laporan_Pemesanan } \\
\hline \multirow{2}{*}{$\begin{array}{l}\text {-User_name } \\
\text { Nama_Admin }\end{array}$} & \\
\hline & \multirow{2}{*}{$\begin{array}{l}+ \text { Update () } \\
+ \text { Insert () } \\
+ \text { Delete }()\end{array}$} \\
\hline $\begin{array}{l}+ \text { Insert }() \\
+ \text { Delete }()\end{array}$ & \\
\hline
\end{tabular}




\section{Gambar 6. Diagram Class Pemesanan Pementasan Seni Tari}

\section{HASIL DAN PEMBAHASAN}

\subsection{Hasil Program}

Tampilan hasil program merupakan tahap lanjutan yang didapat setelah proses perencanaan selesai dan dihasilkan sebuah website yang cukup baik. Hasil perancangan Website Sistem Informasi Pemesanan Pementasan Seni Tari Berbasis Website Studi Kasus Sanggar Cangget Budaya Kotabumi Lampung Utara. Berikut ini dijelaskan mengenai tampilan hasil dari Sistem Informasi Pemesanan Pementasan Seni Tari Berbasis Website Studi Kasus Sanggar Cangget Budaya Kotabumi Lampung Utara :

\subsubsection{Tampilan Menu Utama Pelanggan}

Tampilan menu utama merupakan tampilan utama program yang dirancang peneliti pada halaman utamanya seperti yang terlihat pada gambar 7 berikut ini :

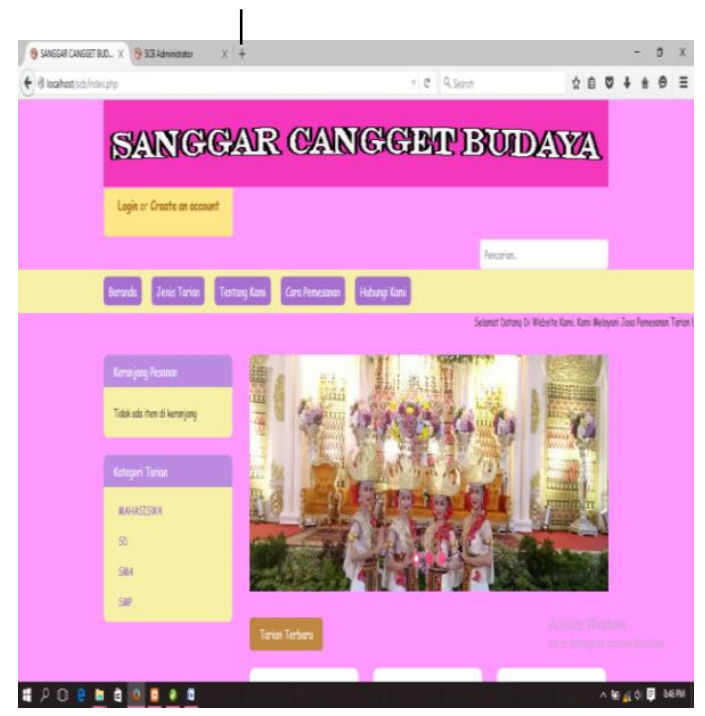

\section{Gambar 7. Tampilan Menu Utama Pelanggan}

\subsubsection{Tampilan Menu Tentang Kami}

Tampilan menu tentang kami menampilkan informasi untuk pengunjung atau konsumen mengetahui profil Sanggar Cangget Budaya Kotabumi Lampung Utara, seperti yang terlihat pada gambar 8 berikut ini :

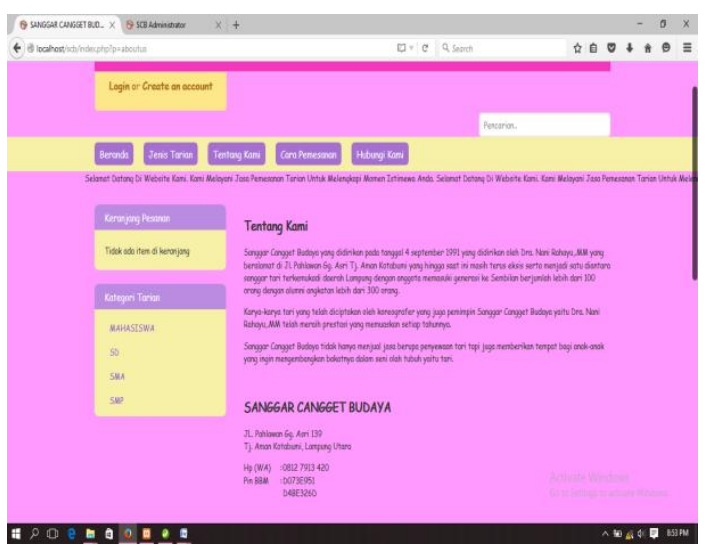

Gambar 8. Tampilan Menu Tentang Kami

\subsubsection{Tampilan Menu Pelanggan}

Pada halaman menu pelanggan akan ditampilkan sebuah form untuk mendaftar sebagai member di Sanggar Cangget Budaya dengan mengisi informasi berupa nama, tanggal lahir dan lainnya seperti di gambar 9 berikut inji : 


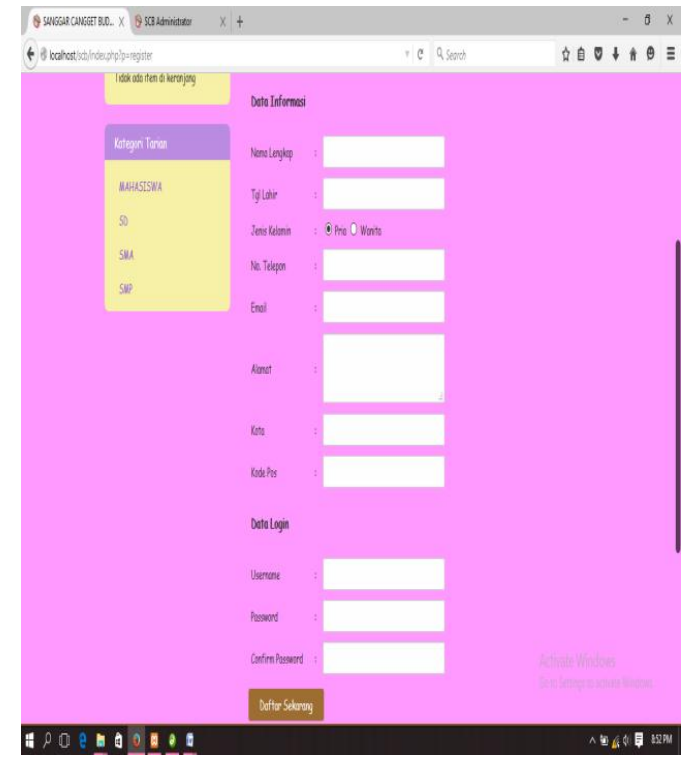

Gambar 9. Tampilan Menu Cara Pemesanan

\subsubsection{Tampilan Menu Login Administrator}

Tampilan menu login merupakan form yang digunakan untuk memasukkan username dan password sesuai hak akses dengan tujuan agar program tersebut dapat dibuka seperti yang terlihat pada gambar 10 berikut ini :

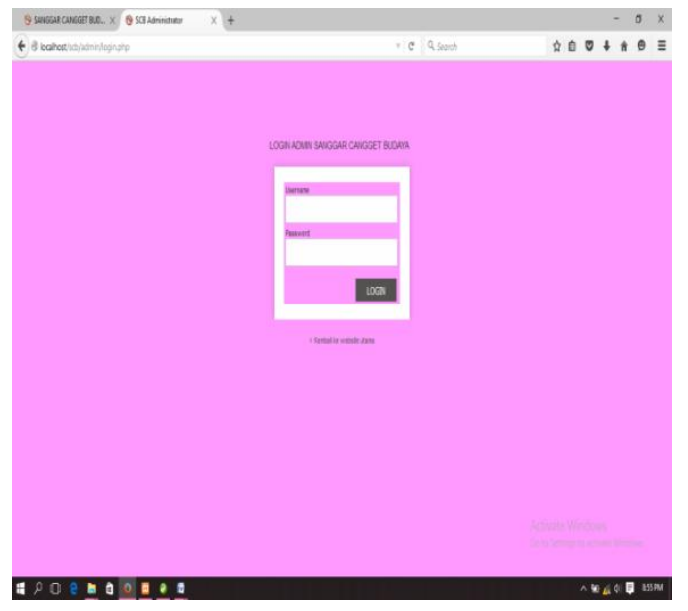

Gambar 10. Tampilan Halaman Login Administrator

\section{PENUTUP}

Setelah menyelesaikan program sistem informasi pemesanan pementasan seni tari di Sanggar Cangget Budaya Kotabumi Lampung Utara, dapat ditarik kesimpulan sebagai berikut :

1. Sistem informasi pemesanan pementasan sei tari ini dapat digunakan untuk membantu pemesanan tarian bagi pelanggan yang cukup efektif yang dapat memberikan peluang lebih besar bagi pengembangan organisasi.

2. Dalam hal pelaporan Sanggar Cangget Budaya dapat memperoleh data dengan cepat dan mempermudah dalam hal transaksi pemesanan tarian dan konfirmasi pembayaran.

3. Dalam hal pengelolaan daftar tarian, pemesanan dan pembayaran dapat dilakukan dengan mudah sehingga dapat membantu meningkatkan kinerja organisasi.

\section{DAFTAR PUSTAKA}

[1] Taufik, Andi. "Perancangan Sistem Informasi Pemesanan Pentas Seni Berbasis Web Pada Sanggar Seni Getar Pakuan Bogor." IJSE-Indonesian 
Journal on Software

Engineering 3.2 (2017).

[2] Jannah, Erliyah Nurul, and Ainul Hidayah. "Sistem Terintegrasi Berbasis Web untuk Pencarian dan Pemesanan Kelompok Seni Pertunjukan." Jurnal Nasional Teknik Elektro dan Teknologi Informasi (JNTETI) 5.4 (2016).

[3] Ardhy, Ferly. "Sistem Informasi Inventory Control Logistik Berbasis Client Server Pt. Keong Nusantara Abadi." Jurnal Informasi Dan Komputer 5.1 (2017).

[4] Parida, Merri. "Sistem Informasi Pengolahan Data Produksi Berbasis Web Pada Cv Semangat Jaya Lampung." Jurnal Informasi Dan Komputer 1.1 (2014): 3-3.

[5] Sita, Muharni. "The Implementation Of A Method Of Ward And Peppard In Information Technology And Information Systems Strategic Planning." Proceeding Icstiem 20171.1 (2018). 